\title{
Presentación intraabdominal de un tumor fibroso solitario de origen pleural, un reto diagnóstico
}

\author{
Intra-abdominal presentation of a solitary fibrous tumor of pleural origin, \\ a diagnostic challenge
}

Pablo Sánchez A. ${ }^{1}$, Cruz Zazpe R. ${ }^{1}$, Antonio Tarifa C. ${ }^{1}$, Inés Eguaras C. ${ }^{1}$ y Javier Herrera C. ${ }^{1}$

Paciente de 58 años estudiada por hematuria, se solicitó una ecografía y se completó el estudio mediante tomografía computarizada (TC) en la que describen (Figura 1) una masa de $9 \mathrm{~cm}$ dependiente del S.VI hepático sin poder diagnosticar la lesión.

Se solicitó una resonancia magnética (Figuras 2 y 3) que identifica una lesión heterogénea con áreas quísticas y de hiperintensidad, sin identificar el origen de la misma, pero sus características sugieren agresividad, por lo que se decide extirpación quirúrgica. Se realizó una resección laparoscópica, en la que se observa un plano de separación con el parénquima hepático y el diafragma como origen, que precisó una resección parcial y sutura del mismo.

El informe de anatomía patológica identificó la lesión como un tumor fibroso solitario de origen pleural.

Los tumores poco frecuentes ${ }^{1}$, originados en la pleura pero que pueden presentarse fuera de la cavi-

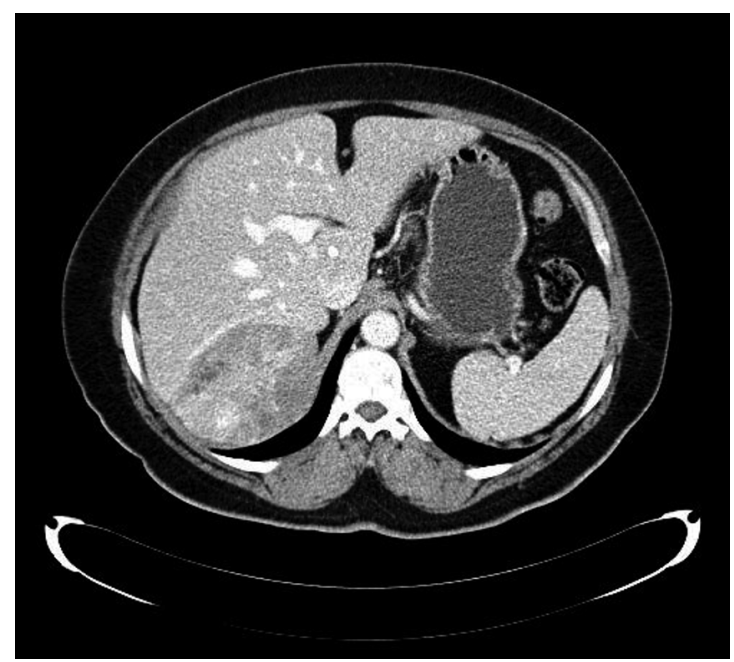

Figura 1. Imagen de la lesión y su relación con el hígado en la tomografía.

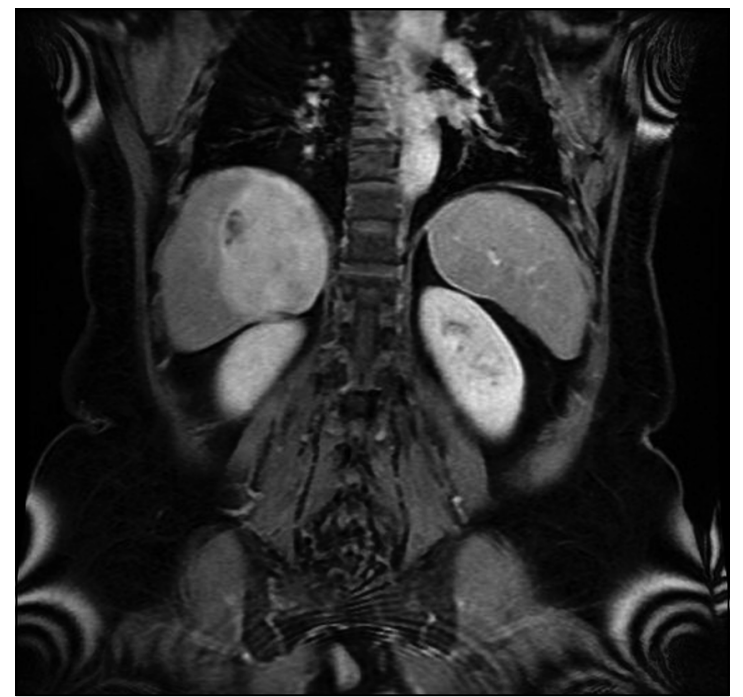

Unidad de Cirugía Hepatobiliopancreática, Complejo Hospitalario de Navarra, Pamplona. Navarra España.

Recibido el 29 de julio de 2018 y aceptado para publicación el 30 de julio de 2018.

Correspondencia a: Dr. Pablo Sánchez A. pablosanchez_84@hotmail. com
Figura 2. Imagen coronal de la lesión en la resonancia magnética.

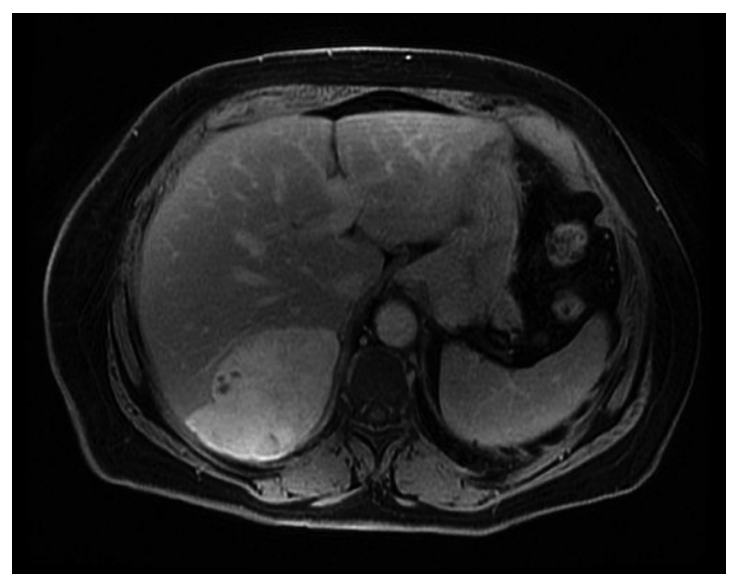

Figura 3. Imagen de la lesión en la resonancia magnética y su relación con estructuras vecinas. 
dad torácica lo cual supone un reto diagnóstico. Son tumores con un buen pronóstico, la supervivencia a 10 años es del 75\%-90\% y el riesgo de recaída del $10 \%-25 \%$.

\section{Responsabilidades éticas}

Protección de personas y animales. Los au- tores declaran que para esta investigación no se han realizado experimentos en seres humanos ni en animales.

Confidencialidad de los datos. Los autores declaran que en este artículo no aparecen datos de pacientes.

Conflictos de interés: no hay.

\section{Referencias}

1. Gold JS, Antonescu CR, Hajdu C, Ferrone CR, Hussain M, Lewis JJ, et al. Clinicopathologic correlates of solitary fibrous tumors. Cancer 2002;94:105768. DOI 10.1002/cncr.10328.
2. Demicco EG, Park MS, Araujo DM, Fox PS, Bassett RL, Pollock RE, et al. Solitary fibrous tumor: a clinicopathological study of 110 cases and proposed risk assessment model. Mod Pathol. 2012;25:1298306. Epub 2012 May 11. https://doi. org/10.1038/modpathol.2012.83.
3. Cranshaw IM, Gikas PD, Fisher C, Thway K, Thomas JM, Hayes AJ. Clinical outcomes of extra-thoracic solitary fibrous tumours. Eur J Surg Oncol. 2009;35:994-8. Epub 2009 Apr 3. https://doi.org/10.1016/j. ejso.2009.02.015. 